\title{
ARGUMENTAÇÃO DE ESTUDANTES DA EDUCAÇÃO BÁSICA SOBRE DILEMAS SÓCIO-CIENTÍFICOS NO PROJETO ENGAGE
}

\author{
ARGUMENTACIÓN DE ESTUDIANTES DE LA EDUCACIÓN BÁSICA SOBRE \\ DILEMAS SOCIO-CIENTÍFICOS EN EL PROYECTO ENGAGE
}

\author{
ARGUMENTATION OF BASIC EDUCATION STUDENTS ABOUT SOCIO- \\ SCIENTIFIC DILEMMAS IN THE ENGAGE PROJECT
}

\author{
Sônia Maria da CONCEIÇÃO PINTO ${ }^{1}$ \\ Silvar FERREIRA RIBEIRO ${ }^{2}$ \\ Ana Karine Loula TORRES ROCHA ${ }^{3}$ \\ Alexandra Lilavati PEREIRA OKADA ${ }^{4}$
}

RESUMO: Este estudo foi realizado no âmbito do projeto Europeu ENGAGE, que propõe o desenvolvimento de habilidades científicas, no contexto da Pesquisa e Inovação Responsáveis (Responsible Research and Innovation - RRI). Questionou-se, como os estudantes usam a argumentação com base em evidência para justificar opiniões sobre dilemas sócio-científicos? Visou a proposição de metodologias alternativas aos professores para melhorar o desempenho dos estudantes no estudo da ciência. A pesquisa foi uma parceria entre a Open University (OU-UK) da Inglaterra e a Universidade do Estado da Bahia (UNEB), realizada em uma escola pública no Município de Irecê-Ba-Brasil, com estudantes da educação básica. Foram identificados todos os elementos da argumentação no decorrer das atividades realizadas pelos estudantes dos três grupos analisados; no entanto, observou-se que apresentaram dificuldades para elaborar uma justificativa com base em evidência, respondendo ao dilema proposto, e descrevendo o pensamento científico de forma sistematizada. $\mathrm{O}$ estudo apontou ainda a necessidade de continuidade da pesquisa com uso de elementos tecnológicos, que apoiassem o estudante com a estruturação das suas ideias.

PALAVRAS-CHAVE: Argumentação. Pesquisa e inovação responsáveis. ENGAGE.

\footnotetext{
${ }^{1}$ Universidade do Estado da Bahia (Uneb), Camaçari - BA - Brasil. Professora Doutora do Departamento de Ciências Humanas e Tecnologias (Campus XIX). Doutora em Difusão do Conhecimento pela Universidade Federal da Bahia (Ufba). Pós-Doutorado na Open University - Reino Unido. E-mail: spinto@uneb.br.

${ }^{2}$ Universidade do Estado da Bahia (Uneb), Camaçari - BA - Brasil. Professor Doutor do Departamento de Ciências Humanas e Tecnologias (Campus XIX). Doutor em Difusão do Conhecimento pela Universidade Federal da Bahia (Ufba). Pós-Doutorado na Open University - Reino Unido. E-mail: sfribeiro@uneb.br.

${ }^{3}$ Universidade do Estado da Bahia (Uneb), Irecê- BA - Brasil. Professora do Departamento de Ciências Humanas e Tecnologias Campus XVI. Doutoranda em Educação e Contemporaneidade pelo Programa de Pós-graduação, do Departamento de Educação (Uneb). E-mail: aklrocha@ uneb.br.

${ }^{4}$ The Open University (OU), Milton Keynes - Inglaterra - Reino Unido. Pesquisadora Visitante do The Institute of Educational Technology. Doutora em Educação e Currículo pela Pontifícia Universidade Católica de São Paulo (Puc-sp). E-mail: alpo3@openmail.open.ac.uk.
}

RIAEE - Revista Ibero-Americana de Estudos em Educação, Araraquara, v. 13, n. 1, p. 207-228, jan./mar., 2018. 
RESUMEN: Este estudio fue realizado en el marco del proyecto europeo ENGAGE que propone el desarrollo de habilidades científicas, en el contexto de la Investigación e Innovación Responsables (RID). Se preguntó, cómo los estudiantes utilizan la argumentación con base en evidencia para justificar opiniones sobre dilemas sociocientíficos? Se trata de la proposición de metodologías alternativas a los profesores para mejorar el desempeño de los estudiantes en el estudio de la ciencia. La investigación fue una asociación entre la Open University (OU-UK) de Inglaterra y la Universidad del Estado de Bahía (UNEB), realizada en una escuela pública en el Municipio de Irecê-Ba-Brasil, con estudiantes de educación básica. Se identificaron todos los elementos de la argumentación en el transcurso de las actividades realizadas por los estudiantes de los tres grupos analizados, sin embargo se observó que presentaron dificultades para elaborar una justificación con base en evidencia, respondiendo al dilema propuesto y describiendo el pensamiento científico de forma sistematizada. El estudio apuntó además la necesidad de continuidad de la investigación con uso de elementos tecnológicos, que apoyasen al estudiante con la estructuración de sus ideas.

PALABRAS CLAVE: Argumentación. Investigación e innovación responsables. ENGAGE.

ABSTRACT: This study was carried out within the framework of the European ENGAGE project which proposes the development of scientific skills in the context of Responsible Research and Innovation (RRI). It has been questioned, how do students use evidence-based argumentation to justify opinions about socio-scientific dilemmas? It aimed at proposing alternative methodologies to teachers to improve students' performance in the study of science. The research was a partnership between the Open University (OU-UK) of England and the State University of Bahia (UNEB), held in a public school in the Municipality of Irecê-Ba-Brazil, with students of basic education. All the elements of the argumentation were identified during the activities carried out by the students of the three groups analyzed. However, it was observed that they presented difficulties to elaborate a justification based on evidence, responding to the proposed dilemma and describing scientific thinking in a systematized form. The study also pointed out the need for continuity of research using technological elements that would support the student with the structuring of his ideas.

KEYWORDS: Argumentation. Responsible research and innovation. ENGAGE.

\section{Introdução}

A educação científica dos estudantes é uma preocupação mundial (CLARK; SAMPSON, 2008; DAWSON; VENVILLE, 2010; DRIVER; NEWTON; OSBORNE, 2000; FISCHER; LEYDESDORFF; SCHOPHAUS, [s.d.]; HODSON, 2003). Dados publicados pelo PISA (2015), revelaram que no Brasil, o desempenho dos estudantes em ciências é muito inferior à média mundial (OECD, 2015a, 2015b). É papel do professor auxiliar os estudantes a tornar o seu pensamento explícito, ajudando-os a

RIAEE - Revista Ibero-Americana de Estudos em Educação, Araraquara, v. 13, n. 1, p. 207-228, jan./mar., 2018. 
esclarecer e dar forma ao seu raciocínio em torno das normas e critérios que sustentam a argumentação científica (HOGAN; MAGLIENTI, 2001; OSBORNE; ERDURAN; SIMON, 2004).

Este estudo foi realizado no âmbito da experiência com o projeto ENGAGE, um projeto europeu, que destaca a importância de preparar educadores e estudantes como coaprendizes, para aprender de modo colaborativo com educação aberta, comunidades, recursos educacionais abertos e como coinvestigadores a partir de práticas investigativas e argumentativas, com discussões sobre dilemas sócio-científicos (OKADA, 2016). Está alinhado com a Pesquisa e Inovação Responsáveis, termo traduzido do inglês Responsible Research and Innovation (RRI), compreendido como uma abordagem que envolve pesquisadores, cidadãos, políticos, empresas e organizações para colaborarem com processos de investigação e inovação com foco na responsabilidade tanto no processo como também nos resultados, conforme as necessidades e expectativas da sociedade (BARDONE; LIND, 2016; COMMISSION, 2013; OKADA, 2008; VON SCHOMBERG, 2013).

Surgiu com a intenção de trazer para o debate reflexões sobre práticas de formação de professores contextualizadas com a RRI, incluindo princípios teóricos, metodológicos e práticos para a educação contemporânea, conectada com a vida dos estudantes e com a sua formação crítico-científica, para enfrentar os desafios do século XXI. Questionou-se como os estudantes usam a argumentação com base em evidência para justificar opiniões sobre dilemas sócio-científicos. Visou a proposição de metodologias alternativas aos professores que permitissem preparar os estudantes para o uso da argumentação científica, justificando opiniões baseadas em evidências sobre dilemas sócio-científicos, colocando a ciência a serviço das necessidades sociais.

\section{Argumentação científica}

Segundo alguns autores, a habilidade da argumentação científica não ocorre de maneira instintiva para muitos indivíduos, mas somente por meio da prática (DAWSON; VENVILLE, 2010; OSBORNE; ERDURAN; SIMON, 2004). Estudos apontam que ensinar como argumentar não apoia o desenvolvimento de habilidades argumentativas (KNUDSON, 1991, 1992) Os estudos de Kuhn (1991) e de Drive; Newton; Osborne (2000), estimulam a visão de que a apresentação de questões sóciocientíficas polêmicas para debate na sala de aula não é suficiente por si só para 
promover habilidades de argumentação. Os professores precisam auxiliar os alunos a tornar o seu pensamento explícito, ajudando-os a esclarecer e dar forma ao seu raciocínio em torno das normas e critérios que sustentam o discurso científico (HOGAN; MAGLIENTI, 2001). Osborne; Erduran; Simon (2004) enfatizam que o raciocínio científico é uma forma especial de discurso que precisa ser desenvolvida e apropriada pelos alunos através de tarefas adequadas e através da "estruturação e modelagem".

Simon et al (2001, p. 2, tradução nossa) apontam que "a racionalidade científica requer um conhecimento das teorias científicas, uma familiaridade com suas evidências de apoio e a oportunidade de construir e/ou avaliar sua inter-relação". ${ }^{5} \mathrm{O}$ conhecimento do sujeito e a experiência pessoal para elaborar argumentos são dois componentes importantes. Para argumentar, os alunos precisam usar conceitos científicos e suas próprias habilidades para fundamentar seu raciocínio, pois quanto mais conhecimento está integrado, mais rica é a sua argumentação.

A habilidade da argumentação científica não é uma tarefa fácil para os estudantes. Eles acham difícil aplicar seus conhecimentos para construir explicações científicas. Estudos recentes mostram que muitos alunos são muito pobres na conexão entre dados e teoria, a fim de validar suas argumentações (HOGAN; MAGLIENTI, 2001)). Schwarz e Glassner (2003) observaram que as crianças não sabem como se conectar, verificar ou contestar argumentos e aplicá-los em outras atividades. Segundo esses autores,

[...] na ciência, as crianças "veem" os argumentos. No entanto, são "paralíticos" em relação às atividades argumentativas das quais os tópicos podem ser os argumentos científicos (por exemplo, "Existem argumentos relacionados?" Ou "Posso conciliar esses argumentos com fatos que conheço da minha experiência pessoal que aparentemente contradiz esses argumentos?" (SCHWARZ; GLASSNER, 2003, p. 232, tradução nossa). ${ }^{6}$

Abordagens para representação gráfica da argumentação surgiram para auxiliar os educadores com o desenvolvimento das habilidades argumentativas nos estudantes, tal como o modelo de Toulmin (1958). De acordo com o modelo de Toulmin um

5 “[...] scientific rationality requires a knowledge of scientific theories, a familiarity with their supporting evidence and the opportunity to construct and/or evaluate their inter-relationship".

6 "[...] in science children "see" arguments. However, they are "paralytic" concerning argumentative activities of which these scientific arguments may be the subject (e.g., "Are there competing arguments?" or "Can I conciliate these arguments with facts I know from my personal experience that apparently contradict these arguments?")".

RIAEE - Revista Ibero-Americana de Estudos em Educação, Araraquara, v. 13, n. 1, p. 207-228, jan./mar., 2018. 
argumento possui componentes fundamentais que o constituem, identificados em sua estrutura básica como dados $(\mathrm{D})$, conclusão $(\mathrm{C})$ e justificativa $(\mathrm{J})$. O raciocínio nesta estrutura parte de um dado (D), considerando a justificativa (J), então chega-se à conclusão (C).

Esse esquema simples torna-se mais completo se forem especificadas as condições para validar a justificativa, indicando um peso para ela. Para isso acrescentase ao argumento qualificadores modais (Q), especificando as condições necessárias para que a justificativa seja válida. O esquema inclui ainda a apresentação de uma refutação (R) que especifica as condições em que a justificativa não é válida. Outro componente pode ser acrescentado para apoiar a justificativa, usando-se uma lei ou um conhecimento científico que dê suporte à justificativa, denominado backing ou garantia (B), baseada em alguma autoridade jurídica ou científica, que fundamenta a justificativa para que seja válida. O esquema completo está representado pela Figura 01.

Figura 1: Modelo de Argumento de Toulmin

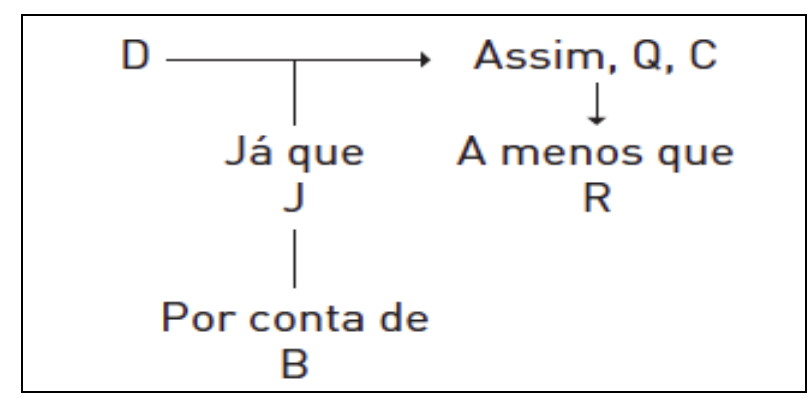

Fonte: Toulmin (1958)

Conforme estudos de Okada (2008), com base no modelo de Toulmin (1958), as justificativas ( $\mathrm{J}$ ) diante dos contra-argumentos (R), tornam-se mais fundamentadas se apoiadas por conhecimentos científicos com fontes ou dados de evidência baking ou garantia (B). Para representar os componentes de um argumento científico para professores, Simon et al (2004) adotam o modelo de Toulmin (1958), aplicado pelos professores para orientar os alunos na estruturação de sua argumentação cientifica e avaliar a qualidade de sua argumentação. 


\section{Metodologia}

Para realizar este estudo, foi criado o projeto ENGAGE BRASIL, através de parceria entre a Universidade Aberta (OU-UK) da Inglaterra e da Universidade do Estado da Bahia (UNEB), que coordenou o suporte e a formação pedagógica dos professores envolvidos com a aplicação de um dos Recursos Educacionais Abertos (REA) do projeto ENGAGE-EU, numa escola da rede pública no Brasil. Ocorreu durante os meses de outubro/2016 (planejamento), novembro/2016 (execução) e dezembro/2017 (encerramento e registros).

Envolveu os autores deste trabalho, pesquisadores visitantes da OU-UK, professores universitários da UNEB-Brasil - formadores de docentes e também professores e estudantes de uma escola profissional de Irecê-Ba: 24 professores, 08 coordenadores e 21 turmas com um total de 478 estudantes dos cursos técnicos de nível médio de Administração Agropecuária, Análises Clínicas, Comércio, Enfermagem, Meio Ambiente, Nutrição, Publicidade e Segurança do Trabalho. A faixa etária dos estudantes variou entre 15 e 18 anos, sendo 60,2\% são do sexo feminino e 39,8\% do sexo masculino.

Em função das características específicas do campo da pesquisa, numa cidade onde existe uma grande incidência de contaminações pelos vírus transmitidos pelo mosquito Aedes Aegypti, optou-se pela aplicação do REA "Exterminar", com a proposição de um dilema sócio-científico para os estudantes, desenvolvido e aplicado no âmbito do projeto ENGAGE-EU, que ofereceu uma série de atividades, materiais multimídia, jogos, links e base teórica para os jovens sobre formas de redução do mosquito usando inovação científica, como a experiência com o mosquito transgênico produzido na Inglaterra e mesocyclopes na Ásia e Brasil (SILVA; ROCHE, 2017; TAM et al, 2015).

O campo do estudo foi uma escola pública ${ }^{7}$ de educação profissional do ensino médio do município de Irecê, no estado da Bahia - Brasil. O município de Irecê faz parte do Território de Identidade de Irecê (TI) e está localizado no semiárido baiano, formado por 20 municípios - América Dourada, Barro Alto, Barra do Mendes, Cafarnaum, Canarana, Central, Gentio do Ouro, Ibipeba, Ibititá, Ipupiara, Irecê, Itaguaçu da Bahia, João Dourado, Jussara, Lapão, Mulungu do Morro, Presidente Dutra, São Gabriel, Uibaí e Xique-Xique.

${ }^{7}$ Secretária da Educação da Bahia. Escolas. Disponível em:


Segundo dados da Secretaria do Planejamento, este Território apresenta características essencialmente rurais, onde $69 \%$ dos estabelecimentos são constituídos de pequenas propriedades rurais, a produção agrícola contribui para a economia do território, especialmente a produção familiar. Sua população é extremamente carente onde 59\% das famílias são beneficiárias do principal programa de transferência de renda do Brasil, o Bolsa Família ${ }^{8}$.

O Território de Irecê encontra-se localizado no Polígono da Seca, portanto, o clima é classificado como semiárido e define-se por apresentar uma estação de estiagem que perdura aproximadamente nove meses no ano, com um breve período de chuva de três meses. As chuvas são irregulares, podendo variar de 200 a 1.000 mm por ano. A má distribuição das chuvas, seguramente, é um dos problemas mais graves dessa região, gerando muitas vezes redução da produtividade ou a perda de plantações.

A síntese do clima é a caatinga, vegetação que permanece a maior parte do tempo seca e aparentemente morta, na qual preponderam os mandacarus, os xiquexiques, os facheiros, os umbuzeiros, as aroeiras, as quixabeiras, barrigudas, entre outras.

Dados da Superintendência de Vigilância e Proteção da Saúde, publicados por meio do Portal de Vigilância da Saúde ${ }^{9}$ revelam que houve um aumento dos casos de Dengue, Zica e Chikungunya entre os anos de 2014 a 2016 no município de Irecê/BA, conforme Quadro 01 síntese a seguir, em que a tentativa de controle e combate ao mosquito Aedes Aegypti se dá com o uso do larvicida "Pyriproxyfen"10" através de 06 (seis) ciclos de trabalho / aplicações por ano.

${ }^{8}$ O Bolsa Família é um programa de transferência direta de renda que beneficia famílias em situação de pobreza e de extrema pobreza em todo o país. O Bolsa Família integra o Plano Brasil Sem Miséria, que tem como foco de atuação os milhões de brasileiros com renda familiar per capita inferior a $\mathrm{R} \$ 77$ mensais e está baseado na garantia de renda, inclusão produtiva e no acesso aos serviços públicos. O Bolsa Família possui três eixos principais: a transferência de renda promove o alívio imediato da pobreza; as condicionalidades reforçam o acesso a direitos sociais básicos nas áreas de educação, saúde e assistência social; e as ações e programas complementares objetivam o desenvolvimento das famílias, de modo que os beneficiários consigam superar a situação de vulnerabilidade. Bolsa Família e Cadastro Único no seu Município. Disponível em: <http://www.mds.gov.br/bolsafamilia>. Acesso em: 02 jan. 2017.

${ }^{9}$ Para maiores informações acessar: <http://www.suvisa.saude.ba.gov.br>.

${ }^{10}$ Para maiores informações acessar: <http://nacoesunidas.org/uso-do-larvicida-pyriproxyfen-para-ocontrole-do-mosquito-aedes-e-seguro-esclarece-oms/>. 
Quadro 01: Dados sobre epidemias no Município de Irecê/BA

\begin{tabular}{|c|c|c|c|}
\cline { 2 - 4 } \multicolumn{1}{c|}{} & Dengue & Zica & Chikungunya \\
\hline $\mathbf{2 0 1 4}$ & 23 & - & 03 \\
\hline $\mathbf{2 0 1 5}$ & 37 & 02 & 02 \\
\hline $\mathbf{2 0 1 6}$ & 68 & 16 & 13 \\
\hline
\end{tabular}

Fonte: Superintendência de Vigilância da Saúde - Bahia (2016)

\section{O Projeto ENGAGE}

O projeto ENGAGE-EU, é mantido com recursos da Comissão Europeia e foi desenvolvido em mais de 80 países europeus desde 2013, com o objetivo de propiciar o desenvolvimento de habilidades científicas nos estudantes a partir das discussões e debates sobre dilemas sócio-científicos atuais (OKADA, 2008). Está voltado para o desenvolvimento das habilidades relacionadas com a coinvestigação, tais como: 1 . Elaborar questão; 2. Interrogar fontes; 3. Examinar consequências; 4. Estimar riscos; 5. Analisar evidência; 6. Elaborar síntese; 7. Criticar afirmações; 8. Justificar opiniões; 9. Usar ética; 10. Comunicar ideias.

Figura 02: Habilidades com a coinvestigação

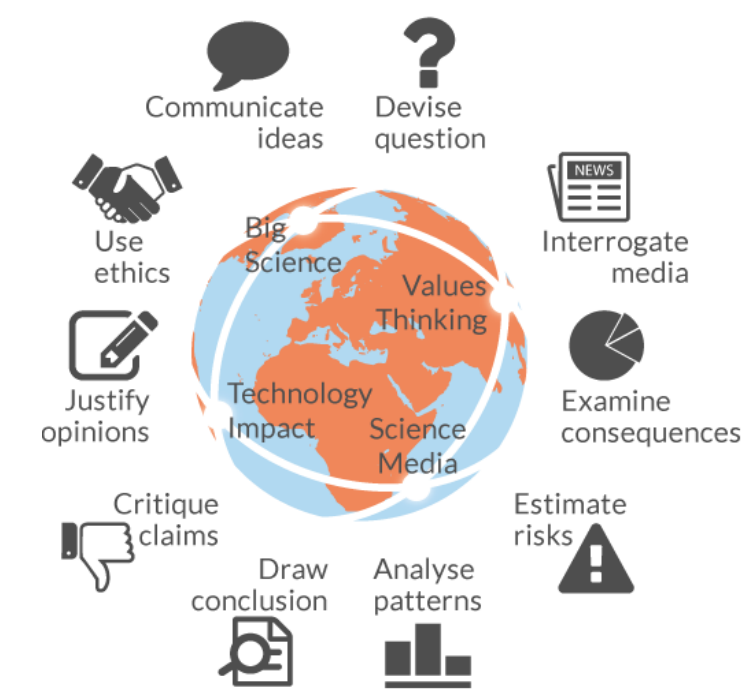

Fonte: Okada (2008)

O projeto está estruturado a partir de três princípios de acordo com a abordagem da RRI: 1) utilização de Recursos Educacionais Abertos - REA, através dos quais os estudantes analisam e aplicam conhecimentos já existentes em questões sóciocientíficas para formação de opinião baseada em evidência; 2) adaptação da prática 
pedagógica, pela qual, em uma sequência de aulas utilizando REA, os estudantes constroem conhecimentos e habilidades necessárias à solução baseada em problemas com conversação. Cabe ao professor viabilizar debates argumentativos para que os estudantes desenvolvam sua capacidade de formar opiniões com justificações mais elaboradas; 3) transformação do ensino aprendizagem, visando a inovação da prática do educador e dos aprendizes via projetos com especialistas, visando resultados mais elaborados com a formação de opinião fundamentada em bases científicas.

\section{Atividades}

O projeto ENGAGE Brasil, fundamentado nos mesmos princípios do ENGAGEEU, foi realizado em três fases sob a orientação dos professores da escola, que participaram do planejamento e da realização das atividades previstas. A mediação pedagógica foi estabelecida para apoiar os estudantes na construção de argumentações com: justificativas fortes, que tem por base a utilização de conceitos científicos; contraargumentos, com fatos usados como fundamento para estabelecer conclusões; dados articulados com conceitos científicos; justificativas bem fundamentadas e; fontes de referências confiáveis.

$\mathrm{Na}$ primeira fase, introdução do tema, os professores apresentaram aos estudantes o dilema sócio-científico "Devemos exterminar o mosquito Aedes Aegypti?". As atividades para esta fase do projeto consistiram em discussões através da realização de uma atividade pedagógica denominada, "jogo da vida" e da construção de um quadro, no qual os alunos registraram o que já sabiam sobre o assunto, o que eles gostariam de investigar, onde encontrar dados e o que aprenderam sobre o tópico.

$\mathrm{Na}$ segunda fase - análise e resolução do dilema - os professores propuseram pesquisas e leituras de artigos sobre mosquitos geneticamente modificados (GM), realizados no Brasil pela empresa britânica Oxitec. Os estudantes sistematizaram ideias e opiniões sobre os riscos e benefícios da utilização de mosquitos GM, avaliaram fontes de pesquisa e foram desafiados a construir argumentos baseados em evidências, para justificar as suas respostas sobre o dilema.

Finalmente os professores orientaram os estudantes a construírem mapas de diálogos (CONKLIN, 2006) para facilitar a construção dos seus argumentos, com uso do software LiteMap (https://litemap.net/ui/pages/about.php). Contudo, no período de realização desta atividade, a internet da escola apresentava problemas de lentidão na 
conexão, dificultando o uso deste recurso online. Diante dessa impossibilidade, optou-se pela construção dos mapas de diálogos, com a utilização de papel e outros materiais escolares disponíveis, mas considerando as bases estruturais propostas pelo LiteMap.

As atividades realizadas durante o desenvolvimento das fases um e dois foram registradas pelos estudantes em Diário de Bordo, classificado, neste estudo, como atividade 01 (AT-01) e o Mapa de Diálogos, proposto na fase três, foi considerado como atividade 02 (AT-02).

\section{Abordagem analítica}

Estas atividades foram mapeadas pelos autores deste artigo, buscando-se identificar e classificar o nível de argumentação dos estudantes nas suas discussões e conclusões, com relação ao dilema sócio-científico proposto. O processo analítico ocorreu a partir da leitura e releitura dos diários de bordo (AT-01) e dos mapas de argumentação (AT-02) construídos pelos estudantes.

Com base em outros estudos (BODZIN; BEERER, 2003; OKADA, 2008; SÁ; KASSEBOEHMER; QUEIROZ, 2007; SADLER; DONNELLY, 2007), a abordagem analítica adotada foi respaldada no modelo de argumentação de (SÁ; KASSEBOEHMER; QUEIROZ, 2007) Toulmin (2001). No entanto, foram considerados quatro componentes do modelo, descritos na figura 03 a seguir, utilizado em estudo anterior por Okada (2008), que analisou o nível de argumentação na escrita dos estudantes de um curso de verão, durante as férias escolares em 2006, no Reino Unido.

Figura 03: Modelo de argumentação de Toulmin

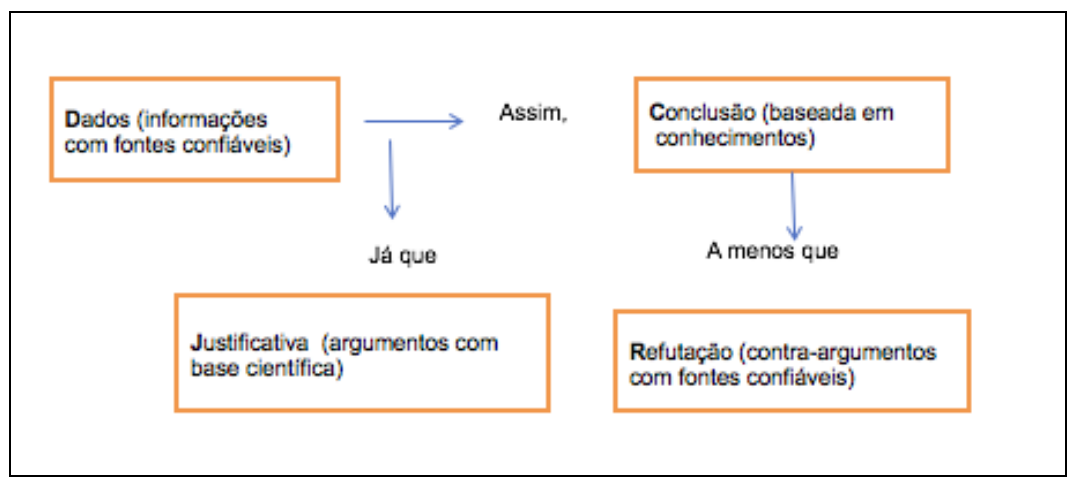

Fonte: Modelo Toulmin (1958) - adaptado pelos autores

RIAEE - Revista Ibero-Americana de Estudos em Educação, Araraquara, v. 13, n. 1, p. 207-228, jan./mar., 2018. E-ISSN: 1982-5587 
Ponderado que a quantidade de dados disponíveis para análise era substancial, foi necessário fazer varreduras e 'cortes' (NORMAN K. DENZEIN; YVONNA S. LINCOLN, 1998) para integrar esta publicação, sem perder o seu valor analítico e importância. Desta forma, optou-se por selecionar as atividades de três grupos de diferentes cursos para compor esta análise que retratou o nível de argumentação dos estudantes ao justificar suas opiniões sobre o dilema sócio-científico proposto no âmbito do projeto ENGAGE-Brasil.

Buscou-se classificar o nível de argumentação dos estudantes participantes do projeto a partir dos indicadores descritos no Quadro 01.

Quadro 01: Nível de Argumentação

\begin{tabular}{|l|l|}
\hline Classificação & \multicolumn{1}{|c|}{ Descrição } \\
\hline Muito fraca & $\begin{array}{l}\text { Conclusões sem justificativas, Refutações e Dados de fontes } \\
\text { confiáveis. }\end{array}$ \\
\hline Fraca & $\begin{array}{l}\text { Conclusões com Justificativas baseadas em convicções, sem } \\
\text { Refutações e Dados de fontes confiáveis. }\end{array}$ \\
\hline Forte & $\begin{array}{l}\text { Conclusões com justificativas baseadas em conceitos científicos } \\
\text { e Refutação baseadas em bons contra-argumentos, mas sem } \\
\text { Dados de fontes confiáveis. }\end{array}$ \\
\hline Muito Forte & $\begin{array}{l}\text { Conclusões com justificativas baseadas em conceitos } \\
\text { científicos, Refutações baseadas em bons contra-argumentos e } \\
\text { Dados de fontes confiáveis, com fatos usados como } \\
\text { fundamento para estabelecer a conclusão bem elaborada. }\end{array}$ \\
\hline
\end{tabular}

Fonte: elaborado pelos autores

A classificação do nível de argumentação em quatro estágios, muito fraca, fraca, forte e muito forte, de acordo com o Quadro 1, considerou a presença e a qualidade, assim como a ausência e a relação entre os quatro componentes do modelo de Toulmin: Dados, Conclusão, Justificativa e Refutação. Os argumentos foram considerados: Muito Fraco (01) - quando identificado apenas o componente conclusões sem justificativas, refutações e dados; Fraco (02) - quando identificadas conclusões com justificativas baseadas em convicções, sem refutações e dados; Forte (03) - quando identificadas conclusões com justificativas baseadas em conceitos científicos e refutação baseadas em bons contra argumentos, mas sem dados; Muito Forte (04) - quando identificadas conclusões, justificativas baseadas em conceitos científicos, refutação baseada em bons 
contra argumentos e dados com fatos usados como fundamento para estabelecer a conclusão.

\section{Análise de resultados}

$\mathrm{Na}$ análise das atividades do grupo 1, verifica-se que foram apresentadas duas respostas. Ambas fazem a opção por não exterminar o mosquito Aedes Aegypti e apresentam os elementos estruturais de um argumento de acordo com o modelo de Toulmin, adaptado para esta análise (veja Extrato 01).

Extrato 01: Análise dos componentes da argumentação do Grupo 01

Atividade 01 (At01)

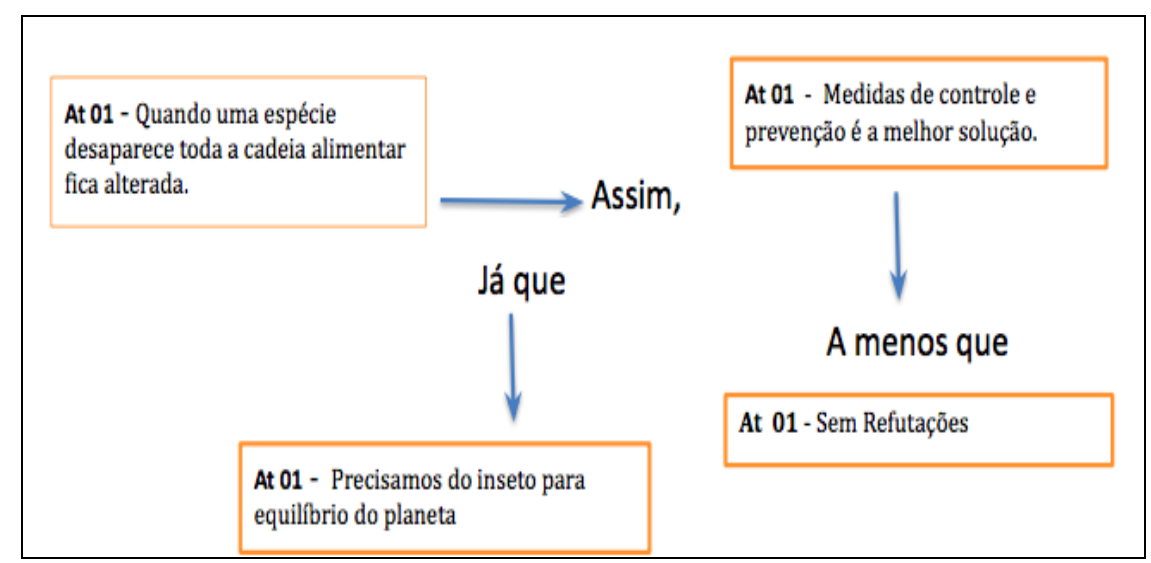

Atividade 02 (At02)

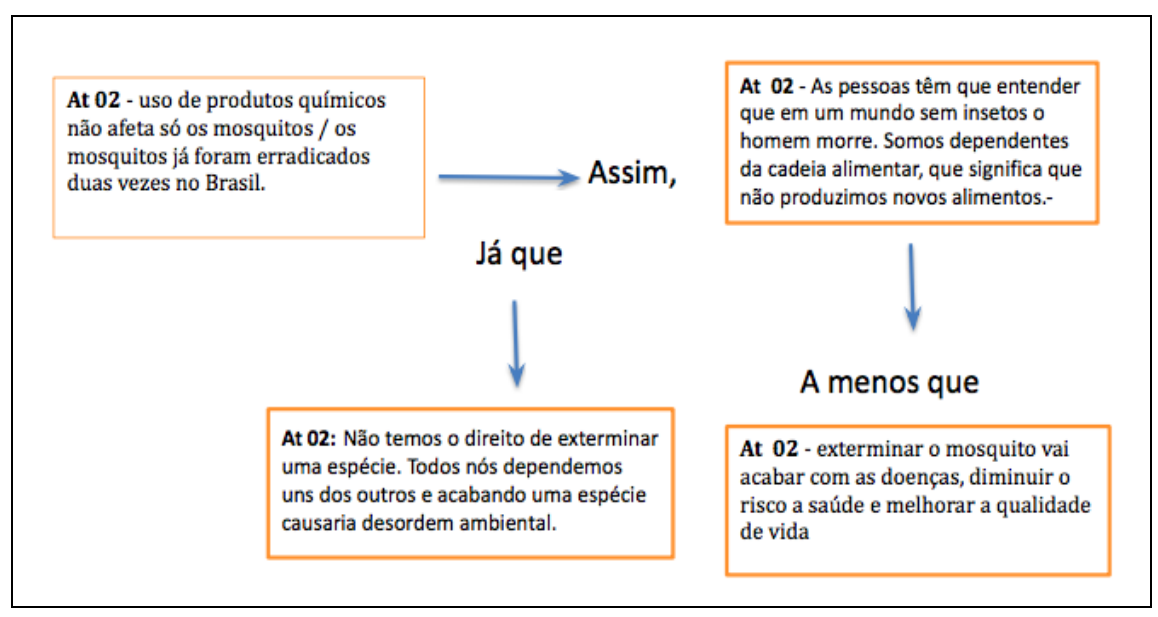

Fonte: elaborado pelos autores

RIAEE - Revista Ibero-Americana de Estudos em Educação, Araraquara, v. 13, n. 1, p. 207-228, jan./mar., 2018.

E-ISSN: 1982-5587 
As atividades que foram analisadas são At01 diário de bordo com textos, jogo da vida e glossário e At02 mapeamento da discussão do grupo com argumentos e texto final.

Na At01, o grupo recorre a um dado sobre a interdependência dos indivíduos que compõem a cadeia alimentar, cita como justificativa a necessidade deste indivíduo (o mosquito Aedes Aegypti) para o equilíbrio do planeta, concluindo que "medidas de controle e prevenção é a melhor solução" para o dilema sócio-científico. Observa-se que não foi apresentada uma refutação, ficando este elemento ausente do argumento.

$\mathrm{Na}$ At02, o mesmo grupo inicia com a apresentação de dados, sendo um científico, referente a extensão dos danos causados pela utilização de produtos químicos no controle do mosquito, uma das possibilidades de combate debatido pelo grupo, e outro dado histórico, que se refere a resultados obtidos no combate ao mosquito no passado, quando o mesmo teria sido extinto no país. Como justificativa o grupo apresenta aspectos éticos e científicos relativos ao impacto da exterminação de uma espécie. A resposta traz ainda uma refutação, apresentando razões para o extermínio e os possíveis benefícios à saúde humana. A conclusão, apresentada como resposta ao dilema científico proposto, na atividade 2 , não faz referências diretas à decisão do grupo, mas deixa subentendida a opção pela preservação da espécie ao referir-se às ameaças à vida humana, como consequência da quebra da cadeia alimentar.

Com relação a pertinência dos argumentos, observamos que no material anexado aos trabalhos, foram realizadas pesquisas em sites oficiais de órgãos da saúde e textos disponíveis na Internet, entretanto, estas fontes não foram citadas nas respostas.

Quanto a qualidade dos argumentos, considerando os critérios adotados para esta análise (Quadro 1), podemos dizer que apesar da presença de todos os elementos estruturantes de uma argumentação as respostas apresentadas pelo grupo 1, nas Atividades 1 e 2 , podem ser classificadas como argumentações fracas. Isto porque a estrutura final dos textos, apresenta argumentos sem a sua devida fundamentação. Não trazem conceitos científicos, dados referenciados, justificativas fundamentadas, nem contra-argumentos sustentados por referências confiáveis. Além disso, as conclusões finais não reúnem os argumentos desenvolvidos nas atividades anteriores, os argumentos previamente desenvolvidos não são integrados para uma narrativa mais completa sobre o que foi aprendido ao longo das atividades. 
Dando continuidade à análise dos resultados, podemos observar no Extrato 02, abaixo, que, o Grupo 2 concluiu, ao contrário do primeiro, pelo extermínio do mosquito Aedes Aegypti.

Extrato 02: Avaliação dos componentes de argumentação do Grupo 02

Atividade 01 (At01)

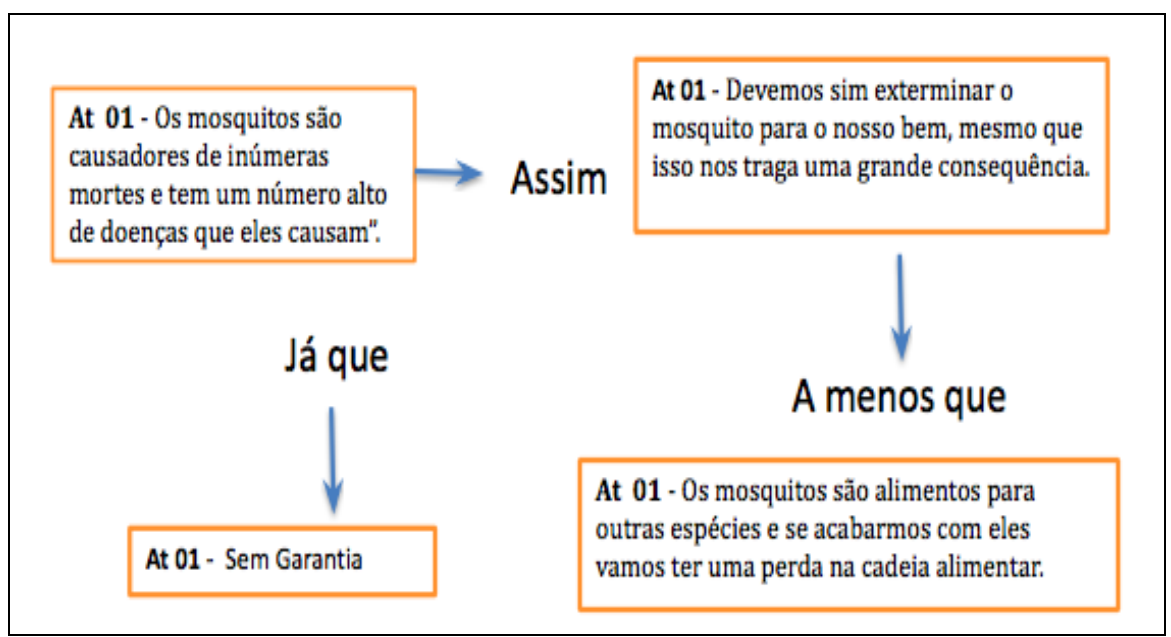

Atividade 02 (At02)

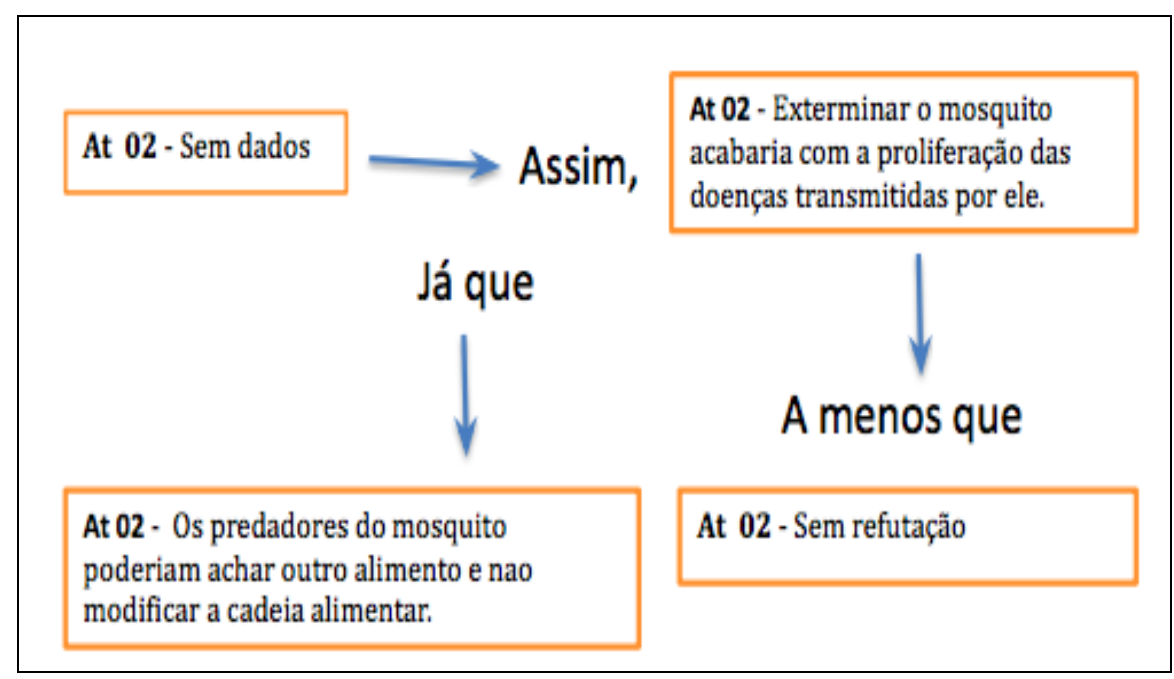

Fonte: Elaborado pelos autores

RIAEE - Revista Ibero-Americana de Estudos em Educação, Araraquara, v. 13, n. 1, p. 207-228, jan./mar., 2018. 
Pode-se ver na At01 - Extrato 02 que a resposta à atividade foi a seguinte: "Devemos sim exterminar o mosquito para o nosso bem, mesmo que isso traga uma grande consequência”. A escolha pelo extermínio já traz no seu texto uma ponderação que demonstra preocupação com as consequências desta decisão. Observa-se, também, que o argumento apresenta dados: "os mosquitos são causadores de inúmeras mortes $e$ tem um número alto de doenças que eles causam", não apresenta justificativas ou informações que deem suporte à sua escolha pelo extermínio, mas curiosamente, apresenta uma contra argumentação, “os mosquitos são alimentos para outras espécies e se acabarmos com eles vamos ter uma perda na cadeia alimentar". A segunda resposta do mesmo grupo, atividade 2, também favorável ao extermínio. Nesta eles não apresentam dados, nem refutações, apenas justificativas: "os predadores do mosquito (Aedes Aegypti) poderiam achar outro alimento e não modificar a cadeia alimentar".

O material anexado aos trabalhos apresenta pesquisas em sites oficiais de órgãos da saúde e textos disponíveis na Internet, que poderiam dar pertinência aos argumentos, no entanto, estas fontes não foram citadas nas respostas.

Quanto a qualidade dos argumentos, considerando os critérios adotados para esta análise (Quadro 1), podemos dizer que a argumentação do grupo 2 não incluiu os elementos estruturantes de uma boa argumentação nas suas respostas. Na primeira resposta foram apresentados três elementos dos quatro requeridos e na segunda apenas dois elementos.

A At01 pode ser classificada como argumentação fraca, por trazer três dos quatro elementos do quadro de referência, mas não apresentar conceitos científicos, dados referenciados, justificativas bem fundamentadas, nem contra-argumentos sustentados por referências confiáveis. Por sua vez a At02, que apresenta apenas dois dos quatros elementos estruturantes e na conclusão não faz referência clara à sua escolha pelo apoio ao extermínio, pode ser considerada muito fraca.

Por outro lado, os argumentos deste grupo revelam uma falta de convicção quanto à escolha feita pelo apoio ao extermínio do mosquito. Os dados, justificativas e contra-argumentos apresentados dão mais sustentação à preservação do que ao extermínio.

Finalmente, analisamos as atividades do Grupo 03, apresentadas no Extrato 03, abaixo. Percebe-se que os quatro elementos do modelo de analise estão presentes, pelo menos em uma das atividades (At02), em resposta ao dilema científico proposto, trazendo dados, justificativa, refutação e conclusão. 


\section{Extrato 03 - Avaliação dos componentes de argumentação do grupo 03}

Atividade 01 (At01)

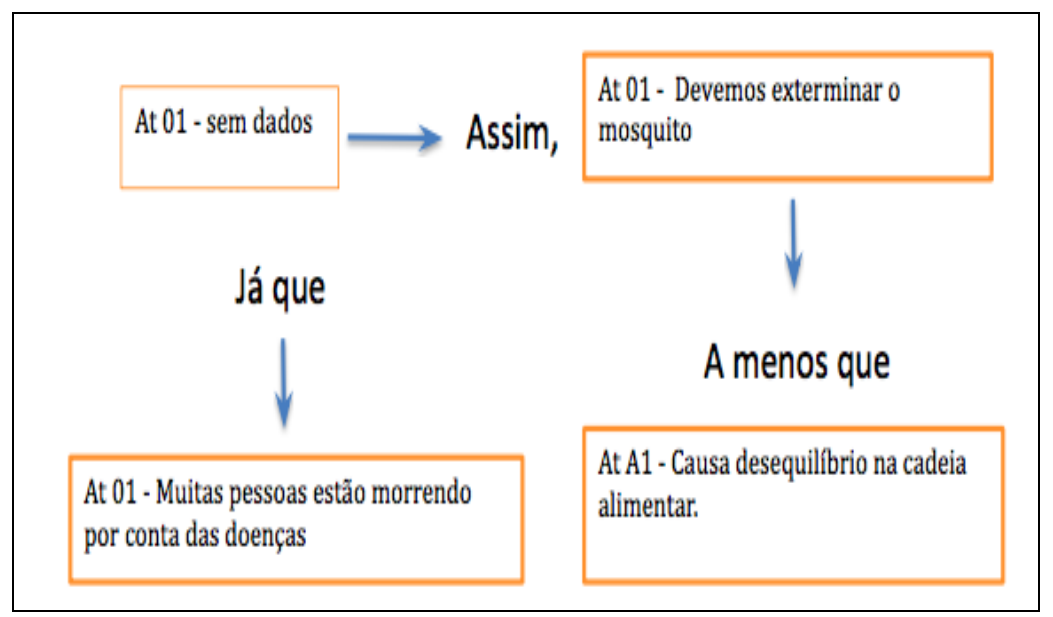

Atividade 02 (At02)

\begin{tabular}{|c|c|c|c|}
\hline \multirow{3}{*}{$\begin{array}{l}\text { At } 02 \text { - Várias abordagens que } \\
\text { envolvem musquitus } \\
\text { geneticamente modificados tèm } \\
\text { side propostas para ajudar a } \\
\text { controlar a propagaçấo de } \\
\text { doenças }\end{array}$} & $\longrightarrow$ & Assim, & $\begin{array}{l}\text { At } 02 \text { - Devemos exterminar o } \\
\text { mosquato porque muitos estão } \\
\text { morrenda pelas virus que ele } \\
\text { transmite. }\end{array}$ \\
\hline & \multirow{2}{*}{ Já que } & & 1 \\
\hline & & & A menos que \\
\hline \multicolumn{2}{|c|}{$\begin{array}{l}\text { At } 01 \text { - Muitas pessoas estão morrendolo } \\
\text { por conta das doenças } \\
\text { At } 02 \text { - Reduçto do múmero de mosquito } \\
\text { é vîtal para proteger a saúle humana }\end{array}$} & & $\begin{array}{l}\text { At } 02 \text { - A remoglo de uma espleie de } \\
\text { mosquito pode permitir que outras } \\
\text { espécies se movam para a outras áreas e } \\
\text { transmitem diferentes virus. }\end{array}$ \\
\hline
\end{tabular}

Fonte: elaborado pelos autores

Entretanto, a exemplo do que ocorreu com os dois grupos anteriores, os argumentos apresentados foram classificados como fracos, tendo em vista não trazerem conceitos científicos, dados referenciados, justificativas bem fundamentadas, nem contra-argumentos sustentados por referências confiáveis.

Apesar disto, as conclusões elaboradas pelo grupo 03, avaliadas no seu conjunto, demonstram uma escolha convicta pelo extermínio: "Devemos exterminar o mosquito porque muitos estão morrendo pelos vírus que ele transmite". Por outro lado, os dados apresentados buscam dar sustentação a esta escolha, quando apresentam a informação de que existe um esforço na busca de meios para exterminar o mosquito: "Várias

RIAEE - Revista Ibero-Americana de Estudos em Educação, Araraquara, v. 13, n. 1, p. 207-228, jan./mar., 2018. 
abordagens que envolvem mosquitos geneticamente modificados têm sido propostas para ajudar a controlar a propagação de doenças". A título de justificativa o grupo afirma que: "Redução do número de mosquito é vital para proteger a saúde humana" e, ao apresentar uma refutação ao argumento favorável ao extermínio afirma que " $A$ remoção de uma espécie de mosquito pode permitir que outras espécies se movam para a área e transmitem (sic) diferentes vírus".

\section{Discussão}

A argumentação científica é uma das habilidades chave para educação contemporânea. Trata-se de um fator essencial para os estudantes estarem aptos a expressarem suas opiniões com fundamentação baseada em conhecimentos, argumentos e evidências (OSBORNE; ERDURAN; SIMON, 2004).

Uma reflexão sobre a questão principal desta pesquisa, nos mostra que os estudantes, participantes do Projeto ENGAGE-BR, conseguiram elaborar argumentos com base nas informações lidas para justificar suas opiniões sobre dilemas sóciocientíficos, porém não alcançaram o nível forte de argumentação, podendo isto ser observado nos três conjuntos de atividades, incluindo as conclusões finais dos grupos. Os principais fatores foram: a falta de descrição dos conceitos com dados, evidências e fontes de referências de modo explícito para esclarecer os argumentos; a falta de justificativas bem fundamentadas, com a compreensão do estudante sobre o assunto; a ausência de contra-argumentos (refutações) de bases consistentes e coerentes com as conclusões e, finalmente, a constatação de que as conclusões apresentadas não estavam adequadamente sustentadas por estes elementos chave da argumentação científica.

Observou-se que os grupos analisados, demonstraram ter compreendido os componentes da argumentação, nas construções das respostas ao dilema proposto no projeto ENGAGE-BR, durante a sua realização, apesar dos trabalhos finais não apresentarem e nem integrarem os argumentos de forma sistematizada.

As argumentações construídas, com apoio da técnica de mapeamento de diálogos, se apresentaram de forma mais consistentes, conforme At02 dos extratos 01 e 03, onde todos os elementos que compõe a estrutura do modelo de argumentação de Toulmin estão evidenciados, ainda que de forma inicial. De acordo O’Brien (2003) a representação gráfica da argumentação pode contribuir significativamente a partir do

RIAEE - Revista Ibero-Americana de Estudos em Educação, Araraquara, v. 13, n. 1, p. 207-228, jan./mar., 2018 
registro permanente do pensamento, maior clareza e rigor no raciocínio, possibilitando o compartilhamento de conhecimento e consequentemente maior compreensão.

O fato de não ter sido possível usar o Litemap, conforme planejamento inicial, em função de problema na internet da escola pode ter comprometido a construção da argumentação dos grupos com todas as suas etapas. O Litemap é um software desenvolvido pela Open University - UK para apoiar o mapeamento de diálogos. Segundo (OKADA, 2008), o uso de tecnologias digitais ajuda a modelar o processo de mapeamento, sendo importante, não só para registro, como também para recuperar argumentos e dados das atividades anteriores e avançar com a discussão, ampliando o conhecimento e as inter-relações entre as várias argumentações.

A discussão sobre o dilema científico proposta no projeto ENGAGE - BR, contribuiu para que os estudantes pudessem construir argumentos para justificar as suas opiniões sobre o extermínio do mosquito. As atividades propostas foram importantes, pois enriqueceram os debates, na medida em que promoviam pesquisas e a estruturação e registros dos seus argumentos. Contudo, embora com a orientação dos professores durante a realização das atividades, os estudantes tiveram dificuldades para sistematizar as suas conclusões de acordo com a análise das atividades, proposta nesta pesquisa. Congruente com O’Brien (O’BRIEN PAT, 2003) e Okada (2008), este estudo, evidenciou que não bastam opiniões com justificativas, ou diversas combinações de argumentos. Para que as justificativas possam ser avaliadas como relevantes precisam ser variadas e baseadas em dados, destacadas de fontes confiáveis e no conhecimento, tais como conceitos aprendidos da área de estudo.

Chegou-se à conclusão que o modelo de Toulmin pode ser utilizado, por professores nas suas práticas pedagógicas, na avaliação da argumentação, durante um conjunto de atividades dos estudantes na perspectiva mediadora (HOFFMANN, 2014), processual, permitindo que os professores possam retomar os aspectos que os estudantes não deram conta, entre os quais o registro das fontes que fundamentam suas argumentações e o detalhamento de suas argumentações, levando a um processo contínuo de construção do conhecimento.

$\mathrm{Na}$ literatura, foi observado que estudos com base em Toulmin (1958), apresentam abordagens variadas em relação a avaliação da qualidade dos argumentos (JIMÉNEZ M. P. ALEIXANDRE; BUSTAMANTE D. JOAQUIM, 2003; OSBORNE; ERDURAN; SIMON, 2004; SÁ P. LUCIANA; QUEIROZ, 2007). Por exemplo, um dos procedimentos é verificar se argumentação tem justificativa plausível ou se possui 
muitas combinações variadas com um maior número de componentes. Outro modo é verificar se a argumentação é apoiada por conhecimento e evidência científica com fontes explícitas (OKADA, 2008), conforme utilizado neste estudo.

Conforme Okada (2008), para que a representação gráfica do modelo de Toulmin seja rica, com vários componentes e combinações, torna-se necessário um conjunto de atividades com discussões contínuas, que indiquem limites do conhecimento atual e, que sejam refutadas ou contra-argumentadas por outros participantes, para que sejam relevantes e consistentes.

\section{Considerações finais}

Podemos concluir que, as práticas de trabalhos escolares discutindo dilemas sócio-científicos mostram-se necessárias e deveriam ser mais frequentes, para que os estudantes possam justificar suas opiniões com argumentações fortes, que articulem os conceitos e teorias científicas; o conteúdo das leituras realizadas, citando as fontes dos textos; os argumentos dos membros do grupo, com posicionamentos a favor e contra, decorrentes das discussões, de modo a desenvolver boas justificativas. Desta forma, os elementos necessários para uma argumentação forte, estariam cada vez mais presentes nas respostas aos dilemas propostos.

Para estudantes do ensino médio profissionalizante, que tomaram parte desta pesquisa, a argumentação científica e a comunicação de justificativas com base em evidência são habilidades-chave tanto para atuação profissional como para estudos acadêmicos do Ensino Superior.

A aplicação do modelo de Toulmin como abordagem metodológica foi útil como um instrumento de análise para os autores, pesquisadores e docentes da Universidade e Escola. O modelo é recomendado em novos estudos para examinar como os estudantes e professores podem usá-lo nas discussões de dilemas científicos para elaborar e avaliar a argumentação para que possam refletir sobre a sua prática e aprimorar a habilidade argumentativa dos estudantes. Os resultados deste estudo mostram o modelo de Toulmin permitiu refletir na visualização gráfica dos componentes da argumentação, sendo útil também para identificar e registrar os argumentos ao longo do processo podendo ser usando tanto para resgatar argumentos nas comunicações orais (discussões) e como escrita (portfolio) 
Novas pesquisas serão necessárias para examinar se o modelo pode ser útil como: 1) instrumento de auto-avaliação para que os estudantes possam avaliar o que faltou e como aprimorar a argumentação, elaborando então justificativas mais completas com todos os elementos e conexões; e, 2) instrumento de avaliação mediadora para que os professores possam usar a representação gráfica para analisar e oferecer feedback para os estudantes, orientando a sistematização e tomada de consciência sobre o registro de seus argumentos.

Recomenda-se a volta a escola com os resultados da análise pelos pesquisadores e professores que deverão apresentar e rediscutir o posicionamento dos estudantes, com relação ao dilema sócio-científico, para que possam reestruturar seus posicionamentos, identificando o que faltou para que seus argumentos fossem fortes, com todos os elementos propostos no modelo de Toulmin. Recomenda-se ainda que esta etapa seja feita com uso da ferramenta LiteMap, considerando que durante o desenvolvimento do projeto não foi possível a sua utilização por problema na rede da escola.

AGRADECIMENTOS: Este estudo foi financiado pela Comissão Europeia e com apoio da CAPES Brasil (bolsista pós-doutorado no Exterior - Ribeiro). Agradecemos a todos atores envolvidos da Escola CETEP Irecê: estudantes e professores; da Universidade UNEB: comunidade acadêmica; pareceristas deste trabalho no Brasil: Profa. Dr. Maria Elizabeth Almeida (PUC-SP) e em UK: Prof. Dr. Tony Sherborne e Profa. Gema Young (ENGAGE - UK).

\section{REFERÊNCIAS}

BARDONE, E.; LIND, M. Towards a phronetic space for responsible research (and innovation). Life Sciences, Society and Policy, v. 12, n. 1, p. 5, 2016.

BODZIN, A. M.; BEERER, K. M. Promoting Inquiry-Based Science Instruction: The Validation of the Science Teacher Inquiry Rubric (STIR). Elementary Science Education, v. 15, p. 39-49, 2003.

CLARK, D. B.; SAMPSON, V. Assessment of the ways students generate arguments in science education: current perspectives and recommendations for future. 2008.

COMMISSION, E. Options for strengthenning responsible responsible and innovation. [s.l: s.n.]. Disponível em: <http://ec.europa.eu/research/sciencesociety/document_library/pdf_06/options-for-strengthening_en.pdf $>$. Acesso em: 11 fev. 2018.

CONKLIN, J. Dialogue mapping - bilding shared understanding of wicked problems. John Wiley ed. England: [s.n.].

RIAEE - Revista Ibero-Americana de Estudos em Educação, Araraquara, v. 13, n. 1, p. 207-228, jan./mar., 2018. 
DAWSON, V. M.; VENVILLE, G. Teaching strategies for developing students' argumentation skills about socioscientific issues in high school genetics. Research in Science Education, v. 40, n. 2, p. 133-148, 2010.

DRIVER, R.; NEWTON, P.; OSBORNE, J. Establishing the Norms of Scientific Argumentation in Classrooms. Science Education, v. 84, n. 3, p. 287-312, 2000.

FISCHER, C.; LEYDESDORFF, L.; SCHOPHAUS, M. Science shops in europe: the public as stakeholder. [s.d.].

HODSON, D. Time for action: science education for an alternative future.

International Journal of Science Education, v. 25, n. 6, p. 645-670, 2003.

HOFFMANN, J. Avaliação mediadora:uma prática da pré-escola à universidade. Porto Alegre: Mediação, 2014.

HOGAN, K.; MAGLIENTI, M. Comparing the epistemological underpinnings of students' and scientists' reasoning about conclusions. Journal of Research in Science Teaching, v. 38, n. 6, p. 663-687, 2001.

JIMÉNEZ M. P. ALEIXANDRE.; BUSTAMANTE D. JOAQUIM. Discurso de aula y argumentación en la clase de ciencias: cuestiones teóricas y metodológicas. Enseñanza de las Ciencias, v. 21, n. 3, p. 359-370, 2003.

KNUDSON, R. Effects of instructional strategies, grade, and sex on students' persuasive writing. The Jornal of Experimental Education, v. 59, p. 141-152, 1991.

KNUDSON, R. The development of written argumentation: an analysis and comparison of argumentative writing at four grade levels. Child Study Journal, v. 22, p. 167-184, 1992.

KUHN, D. The skills of argument. [s.1.] Cambridge University Press, 1991.

NORMAN K. DENZEIN.; YVONNA S. LINCOLN. Collecting and interpreting qualitative materials. SAGE ed. London: SAGE, 1998.

O'BRIEN PAT. Using science to develop thinking skills at key stage 3. New York: Davis Fulton, 2003.

OECD. PISA 2015 Results in Focus PISA. [s.l: s.n.]. Disponível em: $<$ https://www.oecd.org/pisa/pisa-2015>.

OECD. Programme for international student assessment (PISA) - Results From Pisa 2015 - Brazil. [s.1: s.n.]. Disponível em: <http://www.oecd.org/pisa/PISA-2015Brazil-PRT.pdf>. Acesso em: 11 fev. 2018.

OKADA, A. Scaffolding school pupils' scientific argumentation with evidence-based dialogue maps. Knowledge Cartography, p. 131-162, 2008.

OKADA, A. Responsible research and innovation in science education report. 
Milton Keynes: [s.n.]. Disponível em:

<https://www.engagingscience.eu/en/documents/>. Acesso em: 11 fev. 2018.

OSBORNE, J. et al. Enhancing the quality of argument in school science. School Science, v. 82(301), p. 63-70, 2001.

OSBORNE, J.; ERDURAN, S.; SIMON, S. Enhancing the quality of argumentation in science. Journal of Research in Science Teaching, v. 41, n. 10, p. 994-1020, 2004.

SÁ, L. P.; KASSEBOEHMER, A. C.; QUEIROZ, S. L. Esquema de argumento de Toulmin como instrumento de ensino: explorando possibilidades. Ensaio Pesquisa em Educação em Ciências (Belo Horizonte), v. 16, n. 3, p. 147-170, 2007.

SÁ P. LUCIANA.; QUEIROZ, S. L. Promovendo a argumentação no ensino superior de química. Quim. Nova, v. 30, p. 2035-2042, 2007.

SADLER, T. D.; DONNELLY, L. A. Socioscientific argumentation: the effects of content knowledge and morality. International Journal of Science Education, v. 8, p. 1463-1488, 2007.

SILVA, W. M.; ROCHE, K. F. Occurrence of the Afro-Asian species Mesocyclops ogunnus Onabamiro , 1957. (Crustacea: Copepoda ) in the Amazon River basin. v. 1957, p. 209-211, 2017.

TAM, T. et al. Acta Tropica social sustainability of mesocyclops biological control for dengue in South Vietnam. Acta Tropica, v. 141, p. 54-59, 2015.

TOULMIN, S. The uses of argumentEthics, 1958. Disponível em:

<http://www.amazon.ca/exec/obidos/redirect?tag=citeulike09-

20\&amp;path=ASIN/0521534836>. Acesso em: 11 fev. 2018.

TOULMIN, S. Os usos dos argumentos. Martins Fo ed. São Paulo: [s.n.].

VON SCHOMBERG, R. A Vision of Responsible Research and Innovation. In:

Responsible innovation: managing the responsible emergence of science and innovation in society. [s.l: s.n.]. p. 51-74.

\section{Como referenciar este artigo}

PINTO, S. et al. Argumentação de estudantes da educação básica sobre dilemas sóciocientíficos no projeto ENGAGE. Revista Ibero-Americana de Estudos em Educação, Araraquara, v. 13, n. 1, p. 207-228, jan./mar., 2018. E-ISSN: 1982-558

Submetido em: 08/08/2017

Revisões Requeridas: 10/10/2017

Aprovado em: 11/02/2018

RIAEE - Revista Ibero-Americana de Estudos em Educação, Araraquara, v. 13, n. 1, p. 207-228, jan./mar., 2018. 